\title{
Accessibility and The Crowded Sidewalk: Micromobility's Impact on Public Space
}

\author{
Cynthia L. Bennett \\ Carnegie Mellon University \\ cbennet2@andrew.cmu.edu \\ Jeffrey P. Bigham \\ Carnegie Mellon University \\ jbigham@cs.cmu.edu
}

\author{
Emily E. Ackerman \\ University of Pittsburgh \\ eea16@pitt.edu
}

\author{
Patrick Carrington \\ Carnegie Mellon University \\ pcarrington@cmu.edu
}

\author{
Bonnie Fan \\ Carnegie Mellon University \\ byfan@andrew.cmu.edu \\ Sarah E. Fox \\ Carnegie Mellon University \\ sarahfox@cmu.edu
}

\begin{abstract}
Over the past several years, micromobility devices-small-scale, networked vehicles used to travel short distances-have begun to pervade cities, bringing promises of sustainable transportation and decreased congestion. Though proponents herald their role in offering lightweight solutions to disconnected transit, smart scooters and autonomous delivery robots increasingly occupy pedestrian pathways, reanimating tensions around the right to public space. Drawing on interviews with disabled activists, government officials, and commercial representatives, we chart how devices and policies co-evolve to fulfill municipal sustainability goals, while creating obstacles for people with disabilities whose activism has long resisted inaccessible infrastructure. We reflect on efforts to redistribute space, institute tech governance, and offer accountability to those who involuntarily encounter interventions on the ground In studying micromobility within spatial and political context, we call for the $\mathrm{HCI}$ community to consider how innovation transforms as it moves out from centers of development toward peripheries of design consideration.
\end{abstract}

\section{CCS CONCEPTS}

- Human-centered computing $\rightarrow$ Accessibility; Empirical studies in accessibility.

\section{KEYWORDS}

Micromobility, Accessibility, Activism, Governance, Public space

\section{ACM Reference Format:}

Cynthia L. Bennett, Emily E. Ackerman, Bonnie Fan, Jeffrey P. Bigham, Patrick Carrington, and Sarah E. Fox. 2021. Accessibility and The Crowded Sidewalk: Micromobility's Impact on Public Space. In Designing Interactive Systems Conference 2021 (DIS '21), June 28-Fuly 02, 2021, Virtual Event, USA. ACM, New York, NY, USA, 16 pages. https://doi.org/10.1145/3461778.3462065

\section{INTRODUCTION}

Over the past decade, the term "micromobility" has come to flexibly encompass a variety of small-scale, networked vehicles which

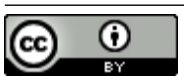

This work is licensed under a Creative Commons Attribution International 4.0 License.

DIS '21, fune 28-fuly 02, 2021, Virtual Event, USA

(C) 2021 Copyright held by the owner/author(s). Publication rights licensed to ACM ACM ISBN 978-1-4503-8476-6/21/06.

https://doi.org/10.1145/3461778.3462065 transport people and goods short distances. Heralded as the answer to dual problems of automobile congestion and insufficient public transit, services such as e-scooters and autonomous delivery robots have quickly evolved to become a focal point of urban initiatives promoting economic development, sustainability, and movement in cities across the United States. For example, Pittsburgh Mayor Bill Peduto curtly summarized the appeal of government participation in innovation initiatives such as shared micromobility. "You can either put up red tape or roll out the red carpet. If you want to be a 21st-century laboratory for technology, you put out the carpet" [53]. Rehearsing the belief that regulation may stifle business advancements, Mayor Peduto and many other government representatives have enthusiastically offered their municipalities as testbeds to gain recognition for supporting the development of what may be collectively called the new smart city $[29,56]$.

Preceding micromobility's rapid ascension, people with disabilities have fought for their right to participate in public [89]. The Disability Rights movement, for example, directly led to United States legislation regulating sidewalks and public buildings such that they are constructed wide enough for wheelchairs and other accessibility mobility tools to traverse unabated [95]. But innovations to public space are still often deployed inaccessibly. Disabled activists, for example, have protested early designs of remodeled Bay Area Rapid Transit train cars for offering less space for wheelchairs to park on board as compared to older models [25], and rideshare companies and governments (permitting their business) have come under fire for not mandating that vehicles welcome wheelchair and service animal users, as traditional cab companies have been required to do [99]. Yet, the impact of proliferating networked micromobility vehicles on public accessibility is under-explored. As such, we take the accessibility of public space as a focal point in examining how micromobility-both small-scale rental vehicles and autonomous delivery robots-have begun to reshape municipal infrastructures and impede disabled people's already limited access to public space $[24,36,39,60,67,68]$.

In this paper, we move across disparate sites of micromobility deployment and attendant activism. Drawing on our own experiences and a set of 24 semi-structured interviews with government officials, disabled residents, public space activists, micromobility operators, and commercial developers, we offer a window into the varied conversations and responses of municipalities, companies, and residents with regard to the accessibility and equity of micromobility. We contribute threaded accounts from multiple stakeholders across the United States, engaging deeply with two distinct sites 
where micromobility has developed over the past few years: Pittsburgh, Pennsylvania and Seattle, Washington. Though we seek to examine these locations in their social and political specificity, we also recognize that micromobility poses access barriers outside the United States and that zooming in on these particular sites may gloss over global impacts [24, 60]. Yet, in analyzing these partial responses on the design, education, and regulation of these devices through the lens of disability studies, we uncover breaks in this emergent, mobile infrastructure and interrogate how micromobility deployments affect people with disabilities.

The explosion of micromobility marks an important phase in the evolution of commercially-driven and publicly-managed infrastructures-those of city streets and sidewalks. Indeed, in the words of one of our interviewees, Jane, a consultant to micromobility companies and city governments, "the street has been turned into a marketplace even though it's our largest public asset.” HCI Research on civic participation in design has long shown that what designers and government officials classify as "synergetic partnerships" may have unanticipated consequences, and that the politics of infrastructure are rife with uneven distributions of power often tipping according to longstanding inequities (e.g., redesigned BART cars which became less accessible for wheelchair users) $[32,100]$. In the case of micromobility, we interrogate how interventions in public space-which may be enacted for altruistic reasons such as sustainability or civic engagement-themselves become barriers to accessible design.

With this paper, we examine specific cases of design and disruption to understand daily maneuvers and evolving policy decisions as webbed and contested negotiations over who has the right to occupy and the responsibility to maintain public space. From our empirical accounts, we draw out sensitivities for HCI designers and researchers to be open to the diversity of bodies (namely, disabled bodies) that share in and contribute to the configuration of public space, particularly when they may occupy the role of a non- or resistant user. As DIS researchers, we often have access to institutional knowledge, resources, and connections to government officials, company representatives, and activists that may help channel concerns on-in the case of micromobility-the speed of particular deployments and a lack of commitment to maintenance. We argue there is a role for design researchers to play in offering insight on tech policy and integration, cutting through the allure of the tech pitch to highlight the limits of current contracts, advocating for more substantial democratic oversight in procurement processes, and calling for the upkeep of technologies and infrastructures over time.

\section{BACKGROUND}

Micromobility encompasses a wide range of shared, small-scale transportation technologies used to aid in moving people and goods. Generally, these devices weigh up to $500 \mathrm{~kg}$ and are set to travel at low to moderate speeds (maximum $45 \mathrm{~km} /$ hour), powered by a combination of electricity and human force [13]. Micromobility, as a term, emerged within commercial fora over the past 5 years, but notions of lightweight, "last mile" vehicles preceded its coining. The Amsterdam-based anarchist group Provo, for example, launched the "White Bicycle Plan" in 1965, which involved painting hundreds of bicycles white (such that they were identifiable) and dispersing them throughout the city for residents and visitors to freely use [54]. This served as a model for the subsequent community bikesharing programs that have been established across the world in the decades that followed.

Early docked bikeshare programs often relied heavily on government subsidies for infrastructure development and service provision. These systems were not meant to be profitable, but rather to extend existing public programs and offerings (e.g., public transport, community wellness programs). The emergence of for-profit "dockless" bikeshare programs, enabled by the rise of mobile phone ownership, shifted this arrangement. German railway company Deutsche Bahn, for example, established its Call a Bike program in 2010, and Chinese micromobility startups Ofo and Mobike expanded their programs rapidly around 2016 [23]. Santa Monica's deployment of Bird in 2017 marked the entry of scooters onto the market, and venture-backed micromobility startups have since become a common fixture across mid- to large sized cities. As of 2018, an estimated 84 million trips were taken in the U.S. [23, 66]. Critically, profit-driven programs rely on frequent usage, which has led to bikes stationed at crowded rights-of-way. Municipalities have responded differently with West Hollywood, CA, Columbia, SC, and Winston-Salem, NC imposing long- or short-term bans on e-scooter technology [12]. Boston, on the other hand, refrained from entering into partnerships with scooter companies, in direct response to neighboring municipalities lodging complaints on scooter cluttering [22] and implementing regulations around their use [35]. Similarly, Portland waited 10 years after its initial 2006 request-for-proposals (RFP) before fully launching their municipal bike-share program, taking in lessons learned from other bikeshare deployments around the United States [90].

Micromobility's ascension relates more generally to the digital translation and occupation of public space. As roadways become more congested, micromobility has spurred increased occupation of sidewalk and curb space. This has proven especially salient for "last mile" urban freight delivery, following heightened consumer demand coupled with efforts to reduce the labor costs associated with traditional courier services. A popular solution among corporate firms centers the development and piloting of automated personal delivery devices (PDDs), small robots which deliver food and other goods (e.g., prescription drugs, packages). Several PDDs have been piloted in numerous cities and on college campuses over the past couple of years. Like some electric scooters, they rely on the use of public sidewalks to function. In the case of recent model state legislation led by Amazon and FedEx, PDDs have been given legal status as pedestrians. This amounts to PDDs gaining rights including those afforded under the Americans with Disabilities Act, such as the right to sue property owners for lack of maintenance of the sidewalks in front of their homes [3]. Though micromobility is heralded as a hallmark for affordable and accessible smart city technology in many transportation circles, rapid and expansive investment in the space has meant that it largely exists in legal grey areas. In turn, cities and states are often left developing reactionary legislation in an effort to determine rules and regulation around safe operation and best practices for integration into city infrastructure. But as recent Amazon and FedEx-backed legislation shows, 
this 'gray area' designation does not always reference missing regulation, but can also result from specific regulation in service of particular stakeholders.

\section{MOVEMENT, AUTOMATION, AND ACCESSIBILITY: A LITERATURE REVIEW}

\subsection{The Networked City}

$\mathrm{HCI}$ has long considered the role of networked devices in public settings. From media facades to in situ voting technologies, researchers explore modes of collective engagement through technological intervention [61, 92, 97]. Vlachokyriakos et al. [97], for example, use low-cost, paper-based materials to situate democratic participation within the contexts of daily life, allowing passersby to vote on local issues via smart posters distributed throughout public space. Taylor et al. [91] similarly reflect on the spatial relations of data produced among residents of a single city street, materializing the social arrangements and boundaries associated with place-based data technologies. More recently, Heitlinger and colleagues [48] trouble the often techno-determinist vision of smart cities promoted by corporate actors, challenging for whom and toward what ends technologies are designed and deployed. Through a participatory and speculative approach, they instead describe their efforts to support urban food growers using traditional gardening techniques.

The role of e-scooters and their potential impact on the urban environment has been explored with observational and speculative approaches [14, 94]. By witnessing scooter-riders move through cities, these papers call for $\mathrm{HCI}$ to play an explicit role in informing the design of emergent forms of mobility and its impact on public space. Two types of proposed intervention comprise of technical systems which may help organize the sharing and upkeep of housing co-op-owned vehicles and augmentations to public space which communicate where different forms of mobility may travel, particularly in landscapes where congestion changes throughout the day. Finally, HCI researchers are leveraging materials science and fabrication to imagine "Soft mobility" devices; these malleable form factors may increase portability and safety when riders share roadways with larger vehicles [81]. Collectively, this work generates a vision for smart cities that centers on enhancing civic life.

Alongside design inquiry into what civic technologies could be, critical computing and science and technology studies scholarship has turned attention to the corporate speculation that surrounds many contemporary smart cities initiatives. Policy scholar Ben Green argues that smart cities proposals tend to distort and exacerbate problems they are purportedly designed to solve, offering up a "myopic reconceptualization of cities into technology problems" and assuming universal consensus about the services extended through technical intervention [38]:3]. Without political debate or democratic decision-making, smart cities initiatives threaten to subtly reform policy and shift political power in ways that are often difficult to reverse. Kozubaev et al. [58], for example, reported on the concerns of Atlanta residents on the putative potentials present in proposals to outfit public housing facilities within smart devices. Additionally, in New York, the Google-backed program Link NYC replaced traditional pay phones across the city's five boroughs with portals providing access to free $\mathrm{Wi}-\mathrm{Fi}$, phone calls, electronics charging, and a tablet for connecting to city services or identifying directions. What wasn't explained with the rollout of this program was that it wasn't simply meant as a public service, but rather it gathered location and behavioral data about everyone who accessed the portal and used that information toward enhancing the company's targeted advertising [57]. Media outlets retroactively decried the Link NYC, remarking on issues of data privacy, ownership, and the lack of options to opt out of data collection for those who'd become reliant on the portals for consistent access to communication [59, 71]. Clear in these questions on data sharing and ownership is the need for robust tech governance that precedes, rather than follows, deployment.

Elsewhere in the cityscape, sensor technologies have been used to outfit streetlights and intersections to eventually allow for autonomous cars to merge seamlessly into lanes without stopping. In the interim, Young and colleagues [105] charted how private firms hold increasing shares of information about urban transportation provision. With this once-public data becoming protected and privatized under terms of competitive advantage through long-term contracts with municipalities, the authors call for the need to codesign legal and technical tools through models like a data trust to ensure resident privacy and enforce legal compliance. Others argue for experimentation in modes of making legible the use of data-intensive technologies toward expanding public oversight and scrutiny [104]. With this upsurge of investment in the space of smart cities, it is necessary to examine the ways in which we as a field approach the topic of connected public space. No longer are these far-off grand visions, but instead smart technologies are increasingly being introduced across a variety of public domains.

\subsection{Accessible Mobility}

In parallel, prior research in HCI on transportation shows how design and technology can address accessibility challenges encountered by people with disabilities. Significant research has focused on pedestrian navigation and public transit accessibility. For example, navigation solutions to support people with vision impairments have been developed to augment wayfinding and spatial awareness [11, 28, 45, 76]. For example, Azenkot et al. [7] communicated navigation information through haptics on a mobile device while Fiannaca et al. [27] examined the use of sonification presented using a head mounted display. Other research has looked more generally at identifying and supporting the information needs of non-visual navigators during their routes, at intersections, and road crossings [11, 41]. Guerreiro [40] and Yang [103] also used audio as the information channel to augment the use of traditionally visual maps during the navigation process. In addition to these solutions to support direct navigation and wayfinding, others such as [79], [80], [108] and [76] have aimed to support the identification and reporting of accessibility landmarks and barriers in the built environment. Project Sidewalk, for example, enables people to contribute to tagging and reporting potential accessibility barriers by reviewing images from open street maps [80]. This data can then be used by accessible mapping applications to support navigators directly or by municipalities to investigate transit spaces for potential issues. Device data and engagement with travelers (as described in $[8,75,80])$ can also be a strong tool both to identify 
barriers and to empower individuals' civic engagement to influence change.

Prior HCI research has also shown that innovations in transportation and mobility are social and contextual. For example, Barbareschi et al. [8] explored assistive technology use in Kenya and illuminate important facets of the value of these technologies. In addition to the functionality offered by the mobility device, in this case a $3 \mathrm{D}$ printed wheelchair, the process of acquiring and configuring the device supports aspects of agency and self-expression. In another work [9], this emphasis on value beyond the specific function of AT is highlighted in the case where a network of people, facilitated through mobile phones and wheelchairs, create an environment where individuals are able to access the assistance they need while maintaining their agency. This is further supported by work to understand transportation systems as a whole including $[55,78,82]$ where inequities in physical access, discrimination, and technological availability significantly influence the overall functioning of a city as well as individual lives. This research shows that the accessibility of public space transcends technical innovation and requires a network of supportive policy and passersby to maintain pathways suited for mobility devices.

Related to accessibility, some recent research has assessed the safety of emerging micromobility, specifically e-scooters. For example, Löcken et al. [62] noted that novice e-scooter riders may not perform turn signals properly, and even when doing so, drivers may not recognize scooter-riders' intent to turn. Other projects focus on supporting scooter-riders' safety. For example, LEaD [93] communicates lighted turn-by-turn directions to keep riders' gaze on the road ahead and [74] aims to ease e-scooter locating through more accurate GPS calculations. Not much research has directly engaged with the accessibility of these mobility devices or their impact on the accessibility of sidewalks, especially with respect to pedestrian navigators.

\subsection{Disability Activism and Making Space}

Now, we turn to disability studies and attendant activism which provides an important backdrop to contextualize our understanding of the contested relationship disabled people keep with public space. One tracing of this history begins with the formalization of Ugly Laws, which were among several ableist and racist responses to slavery's abolition in the United States. Rising in popularity during the US Reconstruction era, these statutes permitted removal of disabled people (disproportionately enforced upon Black and Indigenous people) from public spaces. Mass incarceration of disabled people in what became known as institutions, asylums, and prisons affectively criminalized public displays of disability [83] Additionally, historians including Sarah Rose have shown the labor exploits of such carceral institutions, with disabled tenants feeding capital out and upkeeping daily needs for residential life within [107]. These laws legitimized state surveillance over public space and disabled people, and this subversive power has remained a root of disability activism since. For example, The Independent Living movement asserted redistribution of power to disabled people to maintain agency over where they lived; for most, self-arranging supports was preferred to institutionalization [89]. Subsequent legislation including Section 504 of the Rehabilitation Act of 1973, the
Americans with Disabilities Act, and the UN's Convention on the Rights of People with Disabilities have affirmed disabled people's right to occupy public space and to some degree, stipulate that these spaces must become more accessible.

But historians of science and design Aimi Hamraie [42] and Bess Williamson [101], respectively, teach us that manipulating public spaces such that they are comfortably traversable by disabled people challenges the very fundamentals of architecture and design conventions. Architecture standards, for example, not only concern the construction of safe structures but spaces in which most people are believed to fit. To concretize suggested measurements, template caricatures have been created as embodiments of 'normal' occupants, for whom spaces must be built around. Hamraie and Williamson trace how the rise of rehabilitation engineering after World War II helped to expand the templates available; wheelchair using templates cropped up in textbooks. Ultimately, expanded standards to include people using assistive technologies such as wheelchairs, braille, and captions became the tools of building and evaluating accessibility as legislated in the afore-mentioned laws. Still, as stories of everyday and resistant designs tell, disabled people have largely had to break space and recreate spaces [44, 49, 72, 101].

One sector of academic and activist resistance concerns revealing and reimagining the cosmopolitics of space [80] by reorienting typically surveillant data and infrastructures to zoom in on how institutions and governments figure ideal citizenship through the public spaces they design and maintain. For example, Simone Chess and colleagues [16] wrote of their restroom evaluations, creating maps of single-use restrooms, wheelchair accessible stalls, menstruation supplies, and changing stations to both alert people in need of those resources and demonstrate swaths of campus that remained inaccessible and non-inclusive. Grassroots [73] and academic [80] projects have publicized data about accessible spaces and pathways. Recently, accessibility data have been integrated into mainstream services, such as Google maps, to alert users to inclines during routes and whether approaching public transportation vehicles are wheelchair accessible.

Science and technology and disability studies scholar Aimi Hamraie has taken up this practice, what they call, Mapping Access, to artifact spaces of inclusion as part of intentional accessible worldbuilding [43]. To Hamraie and colleagues, this mapping not only takes the form of $2 \mathrm{D}$ spatial accounting but infiltrates several dimensions with podcasts, tools, writing as to holistically infuse more-than-material space with commitments to access. They propose moving from standardized, fixed conventions on what access means to radical standards, ones that shift and are never met but are characterized by an "unending process of trying to do better" [21].

These literatures scaffold a series of questions which we approach with this work. For example, what kinds of cities are we poised to create? For whom and toward what ends? What must we do as a field to ensure that technology helps create more accessible urban futures? 


\section{METHODS}

This investigation began with a partnership among authors with overlapping interests in and experiences with micromobility. All authors have direct experiences encountering micromobility, and two are disabled pedestrians who have traversed micromobility blocking their paths and have participated in associated activism. Specifically, Cynthia, an accessibility researcher and disabled activist lived in Seattle during a bikeshare rollout where three companies piloted vehicles with almost no regulation; this deployment created several sidewalk hazards for she and her local disabled community. Having been tuned to the impacts of micromobility and coincidentally preparing a move to Pittsburgh, she contacted chemical engineer and disabled activist Emily after reading about her activism to hold delivery robot companies accountable for blocking accessible spaces. The other authors, Bonnie, Jeffrey, Patrick, and Sarah joined the project, adding rich and varied experiences organizing for public space in Pittsburgh, and doing accessibility, networked public IoT, and critical computing research. Our stories intertwine with those of semi-structured interviews with 24 other interlocutors recruited for their experiences with micromobility from government, activist, and industry perspectives. In this paper, they are referred to with pseudonyms. Participants often occupied more than one position, and we list the specific expertise we recruited (followed by the number of participants): micromobility users (5), public space and disability activists (8), people with disabilities who encounter micromobility regularly (7), government workers managing micromobility partnerships with commercial providers (7), current or recent operators who charge, redistribute, and repair micromobility vehicles (5), and current and recent employees of commercial micromobility providers (6).

Semi-structured interview topics inquired into the participant's experience with micromobility, their account of micromobility's evolution in their city and their role in it, who they find is benefiting and harmed by micromobility and what might mitigate harms while preserving benefits. Participants were asked if interviews could be audio recorded. Four workers and activists did not permit us to record with concern for potential repercussions sharing negative views of micromobility. In these cases, the interviewer took detailed field notes. As such, some paraphrasing accompanies direct quotes to integrate these perspectives. As interviews accumulated, the research team triangulated stories with traces from media archives, and in line with traditions of grounded qualitative research [15], we followed actors to other actors by recruiting participants whose perspectives could texture and/or fill in the insights from other participants. Interview transcripts were synthesized into analytical memos and circulated among the research team who discussed and arbitrated themes, convening on those shared in the next section.

In what follows, we present our interlocutors' perspectives on micromobility's development across disparate geographies in the US; we examine micromobility encounters by people with disabilities, and we review activism and responses which aimed to transform policies to better anticipate the access impedances experienced by disabled residents. Across our interviews, we surfaced events and themes insightful to the allocation of public space and accessibility. We then follow by analyzing these events and the patterns they represented in the context of $\mathrm{HCI}$ and disability studies literature on the promises of product deployments and their maintenance and repair.

\section{FINDINGS}

All of our interviewees were avid public transportation supporters, and some were seasoned bikers and enthusiastic micromobility users. One Midwest-based operator Carl, for example, understood the barriers micromobility vehicles posed to his disabled friends when they blocked public sidewalks, but he also enjoyed the exercise and time outdoors riding scooters to and from recharging could provide him. Many of our interviewees expressed hope that small-scale transportation could connect communities, particularly in transit deserts, and disincentivize single-user automobiles. However, their stories illuminated that an ongoing concern in disabled communities was often left out of the popularization of micromobility; their pedestrian safety and adaptive vehicles needs had not been sufficiently considered when they first encountered micromobility. As we focus on micromobility's role in the politics of access to public space, we dial into how these disruptions impacted people with disabilities specifically, and how activists, micromobility company representatives, and government workers attempted to remediate these access concerns while preserving the potential benefits of micromobility. As such, we explicate three types of events which shaped micromobility-laden space for our interlocutors. First, we trace the beginnings of two micromobility programs. Government workers, activists, and commercial consultants in Seattle and Pittsburgh showed how initial motivations carried economic growth interests. However, as programs evolved, rhetoric turned toward deployments of micromobility for public good. Second, we share how a few interlocutors attuned to access and user safety needs experienced micromobility's deployment. Not only did interlocutors with disabilities find disruptions in their paths, but the operators who charge and redistribute supply also found broken devices and insufficient communication channels to companies to report these hazards. Finally, in response, activists centered attention on reclaiming disabled people's right to access public space in calls for greater government regulation and user experience design. We overview these exemplar events next.

\subsection{Planning Micromobility Programs}

According to our interviewees, privately-run micromobility has exploded over the past few years. An influx in venture capital has brought commercial bike- and scooter-share programs to the forefront of city planning and management. In turn, government agencies have scrambled to develop requests-for-proposals (RFPs), evaluate potential programs, and assess deployment plans from micromobility companies. In this section, we dive into the motivations and optics surrounding micromobility's deployment in two locales. At the time of our interviews, Seattle had multiple micromobility offerings, while Pittsburgh was in the midst of deployment negotiations. In 2017, Seattle rapidly transitioned from a publicly-funded, station-based bike share program to dockless micromobility. City officials believed this shift would reduce the investment of public funds and managerial capacity, while decreasing the need for government oversight in day-to-day operations 
(e.g., removing designated station parking would increase ridership). Meanwhile, a nonprofit-run bike share program continued to thrive in Pittsburgh, but government officials sought to learn from early adopter cities (e.g., Seattle) on how best to welcome commercial scooter-share providers. From these examples, we draw patterns in motivation around launching micromobility, both in the more reflective accounts from Seattle and the preparatory work happening in Pittsburgh.

5.1.1 From Public to Private in Seattle. Our first example comes from the large metropolitan center of Seattle. At the time of our interviews, it had been three and a half years since a public bike program was traded in for a privately-owned one. Our interviewees credited the transition to Seattle having the ignoble distinction of being the first major city with a failed public bike system. The Pronto Emerald City Cycle Share program closed due to operational hiccups and low ridership. Postmortem accounts attribute Pronto's failure to sparse deployment locations, strict helmet regulations, and a bumpy transition to City of Seattle ownership [33]. The unsuccessful deployment contributed to negative public perception of the program, further curtailing plans for expansion. In addition to three disabled activists, whose perspectives will be elaborated later, we spoke with two city workers-Josiah and Adam-involved in developing and overseeing micromobility programs; they elaborated on motivations to shut down the station-based bike share and to instead permit commercial companies to operate. First, Josiah articulated complexities of municipal-managed transportation, focusing on the burdens of labor and oversight he saw commercial management taking over from his office's governance. "Cities traditionally put a lot of resources into a bike share system [...] both financial resources and staffing resources. When we switched from a procurement approach to a permitting approach, it downsized to a person managing these programs." Josiah then offered historical context to texture the city's motivation to switch ownership and maintenance models.

The station-based bikeshare system launched in October, not the best time of year for Seattle to launch a bicycling program considering the weather and the darkness of our winters. The system didn't cover enough of the city and the parts of the city it did cover, it didn't cover well enough. So let's say you were walking out of one of the transit stations. There might not have been a bike station right there. It would have been hidden and around the corner and you find that bike station, you rent a bike and then you try and ride to your destination, but you need to find the closest station. And that might be another four or five blocks away from where you're trying to go. There weren't a lot of stations in low-income communities or communities that are predominantly people of color. And that was one of the major course corrections the city was trying to do. There was actually a movement within city council to purchase Pronto. But the mayor's office decided that we were just gonna stop. So the city stopped the traditional dock based system back in April of 2017. And when Seattle became the only major market without a station based bikeshare system that would have precluded dockless from launching, all of a sudden a lot of vendors were calling. So the city quickly spun up a pilot. It came to the radar in May and they launched in fuly. So that it was an exercise in very, very fast city work. Also an exercise in not doing some of the outreach that should be done. But folks really wanted to launch in the summer and not in the winter, which was Pronto's mistake one.

Following the shutdown of their docked bikeshare program, as Josiah alluded, three dockless companies (Ofo, Limebike, and Spin) were approved to each deploy up to 4,000 bikes in a sixth month trial. Since accruing ridership was key to transforming dockless bikes from prototypes to more permanent fixtures on Seattle's streets, these maximums were taken seriously [46]. This led to a new type of congestion, one of bikes which were meant to free up crowded roadways. The influx in bikes set off citizen resistance by car and property owners who cited damage to their vehicles and lawns and by disabled people, detailed later, who had to maneuver the obstacles in their pathways. But Adam recounted the advantage of the learning experience, "A lot of the concepts about how to manage dockless mobility originated in Seattle." To Josiah and Adam, micromobility offered an opportunity for Seattle to streamline resources expended on bike share while gaining outside recognition for setting the standard in governmental oversight of the exploding micromobility industry.

Our interviewees did not recall explicit attention given to the potential impacts a dockless bikeshare without parking instructions would have on access to public space. Further, it would be two years before the city partnered with an organization which rents adaptive bikes meant for disabled riders to leisurely wheel the shop's nearby park, in effort to expand available options for people with disabilities [102]. Finally, micromobility companies have come and gone. At the time of our interviews, riders could rent an electric assist bike from one company, Jump [87] and Seattle was running a new, e-scooter pilot. Riders may rent from Lime, Link, and Wheels [88]; Wheels offers more accessible seated scooters.

5.1.2 Laying the Groundwork in Pittsburgh. The Rust Belt city of Pittsburgh had a different path to micromobility. In 2013, the advocacy group Bike Pittsburgh worked together with the City government to develop a bike share program supported by local foundations and federal funding [47]. The \$1.6 million in federal highway grants required a corporate sponsor, and after several months of searching, wellness organization Highmark Health signed on [20]. A newly formed nonprofit, Pittsburgh Bike Share, operated the bikes with the German vendor Nextbike which supplied the bikes and an electronic rental platform.

But with the city's desire for a post-industrial "smart city" revival, many of its initiatives have since focused on cultivating partnerships. As such, the City of Pittsburgh continued to look for transportation pilot opportunities, responding to the 2015 US Department of Transportation's Smart City (DOT) Challenge [96]. As such, the City's Smart PGH Consortium in 2016 materialized a partnership of philanthropic, university, government, and commercial stakeholders. An outcome of this consortium was Scoobi, a local electric moped company, launched in July 2018 under Pittsburgh's newly formed Department of Mobility of Infrastructure (DOMI). Scoobi's permit allows for scooter parking in existing automobile spaces allocated by the Pittsburgh Parking Authority [10, 26].

Though electric scooter companies have been deployed in cities across the U.S. (as noted in the Background), smaller e-scooters still await state-level approval to operate in Pennsylvania. Still, 
Pittsburgh has moved full steam ahead in anticipation of favorable congressional action such that a pilot launch may quickly follow. Pittsburgh's interest extended further over the next year with the City publishing a RFP for micromobility deployments. Spin, a non-local Ford-owned micromobility company, won the bid by convening a pilot "collective" comprised of fellow new mobility startups [17]. Their charge is to make recommendations and decisions on micromobility policies, technologies, and infrastructural improvements. For example, they recently announced plans to build mobility hubs to facilitate transportation transfers in an effort to ease movement from residential enclaves to business centers across the city. Pittsburgh's conglomerate of corporate and public partners signals the city's intent on investing in micromobility as just one component of economic redevelopment.

We spoke with two Pittsburgh employees-Kathryn and Tannerinvolved in micromobility preparations. Kathryn outlined prospective features of mobility hubs, including adjacency to carpool pickups, public transportation stops, electric chargers, and importantly, large screens with an accompanying smartphone application for citizens to view all transportation options in one place. "Our vision", Kathryn continued:

[....] is that [transit options] should be integrated [...] and there's a number of different factors that go into your decision making. 'Are you traveling by yourself or with others?' 'Are you carrying packages?' 'Are you more sensitive to time or to price?' 'Do you have different abilities that would influence what you would choose?' So, we would like to have these different modes of mobility flow easily one to another. If you can make those decisions known, can we give you a trip that may be using one kind of a device or service to get to another kind of device to service, to get to another one, to get to your destination, rather than needing to independently consult this app, then this app, then this app and cobble it together for yourself?" However, one of Kathryn's colleagues, Tanner, working closely with the plans explained the uncertainty of this vision, "No city tax dollars are going towards this. Funding has come through a foundation to pay for some of the amenities. It's a two-year pilot. At the end of that term, we may determine it needs city funding to make it more viable."

Kathryn further elaborated that if widening ridership motivated the transit centers' convenient combining of multiple transportation options, accessibility could remain an afterthought for prospective commercial partners. "The way we outlined it was that [micromobility company] could start by deploying the standard vehicle so that we can see how that works in our environment. But within that 24month pilot, they needed to work with us. And our intent then is to have an advisory group that would provide that feedback as to what we would be looking for to enhance accessibility." The standard model would assume single riders had normed physical strength, balance, and coordination, and at the time of our interviews, such an advisory council had yet been assembled. However, Pittsburgh government representatives intended to require all micromobility be securely parked, as are Scoobi vehicles. Since reallocating car parking is controversial, Pittsburgh representatives have sought new places to park the smaller e-scooter vehicles. At the time of our interviews, plans were growing to install additional parking for both the nonprofit-managed bike share and commercialized scooter share on sidewalks, with the Americans with Disabilities Act's architecture standards as a guide to determine which intersections were large enough to host these racks.

5.1.3 Corresponding Commercial Preparations. We spoke with five employees of or consultants to commercial micromobility companies who illuminated the inside processes that led to fleet deployments in various municipalities. Each of the five employees brought either expertise in policy or engineering. However, these representatives found themselves distanced from the everyday impacts of micromobility on the ground. One engineer, Ashley, summarized, "It's my job to make things work, I'm not involved in how [micromobility vehicles] are used." Engineers, like Ashley, described the challenges of designing vehicles resistant to frequent weathering and "vandalism," protecting proprietary mechanics and software inside vehicles, and improving vehicle balance and other ergonomics. They agreed that launch date announcements shifted engineering cycles to "breakneck speeds", in the words of engineer Tasha. At this point, priorities even further narrowed to optimize vehicle functionality. Though the employees we spoke with were familiar with accessibility, they were unaware of specific efforts on the part of their employers to produce form factors adaptable for riders with various motor disabilities. Several noted, however, a shift to vehicles with electric assist, and expressed confidence this would widen ridership given the reduction in strength required to operate devices.

Policy strategists like Maxine crafted responses to RFPs, published by municipalities inviting micromobility companies to pitch business partnerships. She worked to ensure that her company "would be selected as one of the operators" in a given municipality. This involved investigatory and anticipatory work to understand the evolving policy landscape across the nation in which bills were being heard, such that she could intervene on the part of her employer. She worked with colleagues to seek favor among legislators and negotiate with municipalities on the rules that would regulate micromobility, the penalties incurred if violated, and the size of the fleets permitted across stages of deployment. Other interviewees noted the fact that RFPs increasingly required them to explain how their companies would encourage "respectful" riding and parking behavior. This condition was frustrating to the micromobility policy strategists we spoke with, as Maxine articulated: "Cities have responsibility to educate the public and possibly being involved in enforcement." In their view, ample stakeholders influence the impact of micromobility, yet companies were being asked to bear the brunt of anticipating and preventing bad behavior. "There are problems with users, regulatory system, legislation, problems with what operators are or are not doing. It's a lot more complex than tech bad or this company bad. There are a lot of competing interests," she continued. Micromobility workers, instead, saw their responsibilities as scoped by vehicle function. Strategically incentivizing user behavior through design or policy to, for example, keep micromobility out of pedestrian rights of way seemed unfair given these vehicles would be just one component in the orchestration of space they occupied. However, all of the representatives we spoke with were aware of the undue burden mis-parked and inaccessible micromobility had on people with disabilities, and the lack of investment in carving out space for emerging transportation 
options. As such, they perceived the imperfect launches of micromobility as drivers of action toward these needed improvements to public space. As Maxine explained, "If [companies] wait until there is adequate infrastructure [cities] wouldn't do anything [...] One benefit of micromobility is it focuses more attention on this discussion." They saw their role as forcing the hand of cities to respond to long festering issues, serving as a catalyst for public discussion and change.

\subsection{Negotiating Micromobility on the Ground}

Most of our interviewees recognized that micromobility vehicles posed particular safety concerns for children, older adults, and people with disabilities. In fact, two interviewees themselves experienced injuries caused by micromobility vehicles that required emergency medical attention. Additionally, interviewees across stakeholder groups elaborated on the parking hazards dockless micromobility posed to pedestrians. In this section, we learn from disabled people's and operators' encounters with micromobility Though government and commercial workers may have spent months planning for launches, micromobility's introduction came as a disruptive surprise to these interlocutors. Both residents and operators alike struggled to report mis-parked and broken vehicles through company sponsored systems. Wages changed overnight for operators and sometimes, companies removed products from cities without notice. Together, they witnessed neglect of the upkeep of micromobility and during our interviews, charted the impacts on their communities.

We begin with Mary, one of the three disabled activists from Seattle who we interviewed. During our interview, she detailed numerous locations where she frequently encountered micromobility vehicles. "As soon as the dockless bike share program launched, I just started encountering the bikes everywhere, left in front of buildings, left at bus stops, left in crosswalks, in curb ramps, in the middle of sidewalks." She also recounted a disruptive experience she had with micromobility. Mary and other blind people organized a series of events to promote fitness in the disabled community. During one such scenic walk, attendees encountered several dockless bikes to the point that one titled himself the "bike mover," as he proceeded to walk ahead and toss bike share vehicles into the grass alongside the pathway, before other attendees encountered them. This damage control helped Mary and other blind walkers to not risk breaking their white canes, a consequence Mary cited experiencing when they accidentally tipped over micromobility vehicles.

Similarly, Lydia, another disabled Seattle resident, was surprised when seemingly all the sudden three companies began distributing dockless bikes around the city. "They just cropped up, scattered across the city on the very limited space I must get around." But these new obstacles were not just a nuisance; they became dangerous. One evening, Lydia encountered a dockless bike at an intersection she needed to cross.

I was on the corner waiting to cross, he [sic] was on the corner crossing the opposite direction, and he left his bike where I needed to go.... I watched the guy get off the bike and put it on the ramp and then walk the opposite direction and I couldn't cross the street to stop him in time. And it was like at 11 PM so it was dark. I had to go and manoeuvre my chair, so I was on the adjacent ramp. So, I was in the part of the street that has cars with the green light so I could get up the ramp.... It was just the most bizarre and prominent example that I think most people could empathize with because why would you see someone across the street in a wheelchair and park your bike on the wheelchair ramp so they couldn't cross the street on the other side? That for people is what gets them to realize the problem, but I encounter difficulties getting around bikes almost constantly.

To Mary, Lydia, and others, dockless bikes added access barriers to their paths, which they noted are already in short supply given the slow pace at which governments have remediated sidewalks to comply with the ADA. But as these disruptions were chocked up to unaware and disrespectful users, next, we turn to potential impacts of PDD's, autonomously moving forms of micromobility which may have even less direct oversight by users.

5.2.1 Absent Ground Navigators - Personal Delivery Devices. With public space becoming increasingly competitive, urban freight delivery has sought after new solutions for crowded cities that avoid traffic. In addition to smaller vehicle pilots such as cargo bikes and drone delivery devices, autonomous ground delivery robots have been introduced to satisfy growing demands for delivery services. In addition to being 15 times cheaper than other delivery services, these Personal Delivery Devices (PDDs) have gained more traction in the context of the COVID-19 pandemic, with model bills by Amazon and FedEx introduced in various states to ease their deployment from a regulatory oversight perspective [63]. In October 2020, Pennsylvania quickly passed its version, with two notable allowances [6]. First, PDD's may be heavier than those in other states, up to 550 pounds. Second, PDDs are classified as pedestrians under traffic code, granting them the right to sue property owners when sidewalks are impassable, among other protections.

Such protections become concerning in the context of how PDDs might share space with disabled travelers, the topic of our next vignette. Our media traces led us to a similar story to that of blind activists in Seattle. This time, second author and disabled activist Emily Ackerman who, like Lydia, is a power wheelchair user, was disrupted by a PDD. Emily first noticed human-assisted delivery robots being calibrated on the sidewalks of Pittsburgh in the summer of 2019. But she also noticed that when the humans disappeared and the robots travelled alone, she found no local press release or public awareness about what the robots were or how humans could expect to interact with them. Our prior-referenced interviews with Pittsburgh's government workers managing micromobility did not concern robots; Unlike provisions of dedicated parking to promote that sidewalks remain clear of bikes and e-scooters, pilot robot deliveries had not been anticipated with such intention. The consistent annoyance that was autonomous delivery robot pilot turned into an egregious safety hazard for Emily one day:

I couldn't really see the street in front of me. I was just waiting behind a lot of people and people started crossing the street. So, I followed them. And when I got in the street, I realized that the robot was sitting in the curb cut on the other side, and I thought, 'okay, well it'll move by the time I get there.' But when I got there, the robot was still directly in the curb cut, maybe three inches from the edge. And so, I was immediately panicked because the walk sign was ending and I needed to quickly decide, do I go all the way back across the street? I 
wish I thought of going around the corner [to another curb cut]. But I just panicked. And I knew that sitting in front of it wasn't going to make it move. So, I ended up bumping up the part of the curb cut that slopes up, which is dangerous for me because I could get stuck easily. It's also painful to have such a sharp jolt to my body. [After ascending the curb] I turned around. It was just still sitting there, and I was just so upset that this robot had put me in danger [18].

Following their dangerous encounters with micromobility blocking their safe means of crossing a street, both Lydia and Emily witnessed insufficient responses. In Seattle, Lydia learned from another wheelchair user that while on her employer's campus, she should request their dedicated law enforcement to remove improperly parked bikes. She explained how the solution, to her, was a "halfassed" example of not actually addressing her insufficient access to public space. "I wouldn't want to wait half an hour, 45 minutes, to get into a building because a bike's in the way. [The solution] wasn't being announced in a structured formal way to make sure everyone knew it. I accidentally happened to find out that there was a solution. It was not widespread knowledge in the first place."

Focusing back on Pittsburgh, Emily began to take action by posting on social media, tagging the robot manufacturer and university where they were deployed [1]. The vehicles were immediately removed upon the call for public accountability, but the gesture was short lived. Robots from the same company were deployed again four days later and pilot deliveries commenced until they were discontinued because of the COVID-19 pandemic. But their re-entry into public space occurred again without any press releases. During those four days, Emily communicated with the manufacturer who initially apologized for the bug in the technology but according to Emily, "the next day Starship issued a retraction and said that they were happy to see that I got around it." Media judgment continued, impacting Emily's safety in off-line spaces. "That caused a lot of backlash at me for "whining," which I didn't, I always said I got around it. I never said I was slammed. I was raising an issue, a very dangerous issue, and the internet turned into this very scary place of, 'Well, you didn't get hit by a car, right? You didn't die. You ruined this good thing for us. Come back when you're in the hospital.' And I woke up to all these really vile comments, and it was like a 180 and I doubted myself and I felt in danger and not safe to walk around my own campus" [18].

Emily continued with her online advocacy despite this backlash [2]. Though there was increased recognition by the disabled community, micromobility companies have continued to innovate and deploy, leaving the public unsure of how these incidences impact their processes and concerns for safety and accessibility [36] For example, one year later, during the legislative session which ultimately approved PDD's to operate in Pennsylvania, Representative Innamorato asked about PDD's impact on individuals with disabilities, citing Emily's experiences [51]. Her experience with Starship was known both to the PDD industry representative as well as the Chairman of the hearing. However, the concerns were merely addressed with a comment that the state hoped that local municipalities would ask for adequate operations plans to prevent obstruction of ADA accessible areas given their closer relationship to advocates and communities. In this case, access and safety concerns were punted to local municipalities which would then have no recourse to overwrite state-level policy.

The difficulties of combatting disruptive micromobility emanated across interviews. Apart from stories of similar disruptions to their commute by disabled interviewees, government workers and micromobility operators shared the perils of communicating and relieving micromobility disruptions. For example, throughways from end users to micromobility companies were so unsuccessful that some municipalities integrated pedestrian micromobility reports into their 311 non-emergency service. To one government worker on Los Angeles's micromobility programs, Juan, the extra work of facilitating communication between end users and micromobility companies on the upside, streamlined micromobility reporting into the same mechanism citizens would use to make many reports about public space, and also gave his municipality a paper trail to hold companies accountable for responding to concerns within a specified time.

All five operators we spoke with elaborated on the rapid wear and tear done to micromobility vehicles given their heavy usage and sometimes intentional user and bystander damage. Yet, they had no way to contact their employers directly and reporting broken vehicles could come at a cost to their wages. One operator from the midwestern United States, Carl, charged scooters to supplement insufficient Social Security and retirement income. At the time of our interview, his supplemental income had dried up as a month prior, the e-scooter company disappeared from town without warning the gig workers upon whom it relied. Nonetheless, he shared how damaged vehicles connected to his employer's decisions. "I was not supposed to do anything to scooters for repair. I was supposed to mark them for repair and let somebody else pick them up. But after I've walked a half an hour to pick up a scooter, if I could still charge it I'd get paid for it. So I put scooters back out with no brakes. And that [policy] was evidence to me that [company] did not care, not only about us, but care about the people writing them. When I went to the emergency room [for micromobility-related injury], I asked the doctor and he said someone was coming to that emergency room every day with a scooter injury. This is a town of about 80,000 . This isn't a huge community. And for the doctor to say he was seeing a scooter accident every day; the scooters are not safe." Some operators we spoke with compromised ethics given their reliance on the gig work to offer them flexible employment, which was helpful given their health, care responsibilities, and other life circumstances. But their experiences charging thousands of scooters across the United States expanded our understanding of micromobility's disabling impacts. Their placement in pathways could inhibit disabled citizens. But labor and communications policies disincentivized the citizenry and operators from reporting or repairing mis-parked and broken vehicles, exacerbating their potential negative impacts. In some municipalities, like Juan's, this neglect necessitated government intervention to facilitate communication. But risk to public remains as broken vehicles were returned to public spaces after being charged, and stories by disabled pedestrians like Mary, Lydia, Emily, and others remain unaccounted by micromobility manufacturers. 
5.2.2 Accessibility Activism and Evolving Regulation. This section details some organized activism, like that called for in the previous section's accounts, and associated government responses. Mary and other Seattle-based blind activists who were disrupted during their fitness promotion walk started reaching out [106] and attending frequenting meetings with their municipalities micromobility and public transportation representatives. But it took multiple actions for them to be taken seriously. Eventually, Mary and other activists were granted regular dialogue about micromobility development under consideration. Mary detailed this process, "We started to speak at city council meetings, because they had nothing in place for where the bikes were supposed to be parked, or any education or anything. So the city staff said they would work with us. We reached out and they didn't respond." Mary contacted local news media, and some local news programs ran stories depicting blind residents encountering several mis-parked micromobility vehicles $[19,39,65]$. After, municipal workers charged with collecting public comments about micromobility pilot programs in progress invited the advocacy organization to a dedicated meeting. But facilitators requested questions be handwritten on cards. Mary leveraged this inaccessible inquisition for blind participants as an opportunity to publicly demand a change in format to spoken questions. She described this direct resistance at the meeting as a turning point after which she and other blind activists noticed change. For example, micromobility companies then sponsored disability-led creation and dissemination of educational videos teaching riders in both Seattle and Portland, Oregon, which hosts e-scooters, appropriate micromobility parking [77]. Additionally, the municipality conducted quarterly audits in 2019 to calculate and penalize companies for mis-parked micromobility [84-86]. Finally, the municipality used micromobility operation permit fees collected from private companies to build micromobility parking spaces in urban areas where sidewalk parking would inhibit an accessible rights-of-way [69].

One response to inaccessible micromobility, in particular, has garnered mixed reviews. Adaptive bike programs have been praised for their increasing access to bikes generally but critiqued for not being a substitute for accessible micromobility. However, Seattle municipal worker Josiah explained that the rationale for supporting recreational adaptive bike programs stemmed from unsuccessful attempts to incentivize micromobility companies to develop and deploy additional vehicles accessible to riders with mobility disabilities. "We really wanted to see adaptive bikes become part of Seattle's fleet. So we tried to incentivize them as best we could. [Company] developed a trike, but they never put it into production. So we took a portion of the permit fees and funded one of the largest adaptive sports providers in the US to open up their adaptive cycle center seven days a week and made all rentals free [102]. We saw rentals raise 250 to $400 \%$. "Joshua, a Portland municipal worker described a separate program in his municipality called Adaptive BIKETOWN [3], was developed with a working group including disabled people. "So it's a fee for a two hour ride. So you go in person to this bike shop and you will be fitted with the appropriate bike with staff that's been trained. The working group decided that they wanted their adaptive program to be focused on recreation and not so much as getting from point to point."

However, our disabled interlocutors pointed out that if an accessible recreational bike program was informed by disabled people, the separate character of these adaptive bike shops did not render them a type of equal access. These adaptive bike shops required users to come to them, unlike micromobility which is regularly rebalanced to meet customers where they are. Further, the locale of adaptive bike shops in the vicinities of our interlocutors gave them the impression the intent was for them to be used for recreation rather than productivity. Shops near waterfronts and far-flung parks were incidentally in public transit deserts. Further, according to their website, Seattle's adaptive bike program ran during warmer months only and has returned to a fee-based structure as their partnership with the city concluded [70]. As interviewees understood micromobility was meant to be an answer to 'last mile' transportation needs, where a user may speed their trip from home to a bus station or from a transit stop to work, offering accessible bikes for rent near trails and parks did not solve their actual transportation needs. Michelle is a long-time disabled biker who found the recreational character of adaptive bike programs particularly off putting. She would like to partake in micromobility offerings, but the standardized bike designs available were inaccessible to her. Michelle's ongoing advocacy has consisted of demanding change to the ecosystem in which inaccessible micromobility is situated. With bikers and wheelchair users on her university campus, she has demanded more funding be put into installing bike racks that can secure larger bicycles. Further, her coalition demanded that campus bike repair shops be outfitted with supplies and expertise to upkeep adapted bikes, like the recumbents accessible to her. Demands to her municipality which is charged with reviewing micromobility company permits included requests for what she considered basic access, "So one of the things that [government administrators] should be insisting upon is a certain percentage of a variety of adaptive bikes in the bike share program and that the ability to use those is no more onerous than it is for able-bodied people to check out the standard bike share." Adaptive bike shops have been celebrated by government workers and the media for providing needed accessible recreation. While disabled interlocutors acknowledged these benefits, they did not perceive recreational bike rentals equal access to the proliferating micromobility around them, and the discontinuation of one adaptive bike partnership highlights the precarity of some proposed accessibility solutions.

In summary, even the successful partnerships that blossomed among activists, disability educators, and government representatives, did so often at the request of people who had already been disadvantaged by micromobility. Unfortunately, micromobility's introduction into their public space communicated to them that accessibility was an afterthought.

\section{DISCUSSION}

Shared mobility has an activist history. Until recently, the programs funding and operating such systems have not been in service of making a profit, but in enabling ready movement throughout public space. The changing character of shared mobility-from public and nonprofit to privately-owned-has unsurprisingly refreshed both government and activist concerns about gaps in service that may occur when vehicle distribution is financially driven. Interwoven with our personal experiences and archival traces, our interviews 
with government and commercial workers, disabled residents, micromobility operators, and activists alike, contribute a tapestry of experiences with micromobility that inform how its deployment, maintenance, and repair impact disabled people's access to public space, a right long fought for and still contested. First, we combine perspectives to share mismatches in how interlocutors and media depicted the deployments of micromobility. Next, we trace how stakeholders have interpreted micromobility vehicle owners' maintenance and repair and the government and activist responses that have served to evolve and continue to resist commercialized micromobility.

\subsection{Quiet Partnerships, Uneven Deployments}

In our interviews, government officials rehearsed the promises made by venture-capital backed micromobility firms seeking to forge partnerships. They outlined how such agreements served to minimize bureaucratic burden and administrative labor, while introducing technologies to respond to the widely recognized "last-mile" problem of existing public transit. With many municipal agencies and departments facing budget cuts, it's perhaps of little surprise that these appeals would be so well received. The offers to contract out shared mobility services also held the allure of entree into a class and category of city deemed "innovative." Through our conversations, officials frequently compared their own city's development projects and tech infused deployments to others, suggesting an innate sense of competition between municipalities vying for press and prestige (particularly among those associated with bygone industrial economies like Pittsburgh). The managerial vision of micromobility was posed as a win-win to cities: a chance to avoid expenditures associated with deployment (in labor hours and maintenance) while garnering praise [31].

Behind the scenes, much went into making these proposals enticing. Policy analysts at micromobility companies spent their days combing through RFPs, monitoring legislative trends, and crafting bids prime for easy procurement agreements. However, once contracts were signed and form factors introduced to the streets, it quickly became clear how little attention had actually been paid to how these devices might fit within the social and infrastructural landscape of the city. Namely, as expressed across our interviewees, the deployment of micromobility came as a surprise to those moving through public space. For people with disabilities who newly found micromobility blocking their paths, in particular, it was evident that their movement with wheelchairs, canes, and other mobility aids had not been considered.

Scooter shares and other micromobility platforms are regularly heralded for the convenience they present to riders, who no longer have to purchase and maintain a vehicle to enjoy it. Yet, scooters and other micromobility devices are designed to serve normed, nondisabled bodies. The luxury they provide is not afforded to disabled riders who remain underserved by public transit options $[25,55,75,99]$ and are often reliant on insurance coverage to secure the devices they need for movement (e.g., wheelchairs, canes) [98]. Further, as previous research $[62,74,93]$ and our operator interlocutors confirmed, these new forms of mobility may pose hazards to all who encounter them, raising the need to widen concerns of accessibility and safety to non-users, resistant users, new users, to the operators responsible for charging and upkeeping devices, and to pedestrians and operators of vehicles encountering micromobility. While vehicles may signal a new transportation option for some, their disruptive placement on the sidewalks leads to a reordering of public space such that it is newly immutable and inaccessible.

"Rolling out red carpets" by having a light touch approach to regulation could put municipalities on the map by virtue of extension. Failing to do so, Pittsburgh and Seattle officials feared, would drive economic opportunities away and mark them as difficult to work with in perpetuity. Yet, the patchwork approach to regulation brought on by micromobility only extended confusion around their introduction. Who was responsible for the devices if blocking rights of way? How about those left in disrepair? If a car were left strewn across a lane of street, the owner would likely expect their vehicle towed and to receive a hefty fine. With e-scooters and electric bikes pilots, liability was often obscured. Cities struggled to hold companies to account after the terms of their pilot agreements were set, suggesting that the tentativeness (perhaps intentionally) allowed for regulatory grey areas. Meanwhile, legislation like that backed by Amazon and FedEx sought to cement pedestrian rights for PDDs, making future legislation to strengthen pedestrian rights a difficult avenue for protecting people. Turning attention instead to riders, officials prepared public materials on "respectful" use in hopes that proper training would resolve the issue. Yet, it's clear across our interviews with residents that more needs to be done. Rather than some disruptive force upending the ways we consider the curb, we argue for micromobility as a "legal-material hybrid," in the words of Sheila Jasanoff [52]. It exists to take up and move through space but cannot do so without legal allowance. The regulatory power of traffic lights, to use Jasanoff's example, depends on an enforceable traffic code that equates red with stop.

Specific policy and design explorations illuminated through this work concern protecting human citizens, particularly those already disenfranchised by inaccessible pathways and transportation options, rather than allowing vehicles into the category of pedestrian. Additionally, pilot phases must not evade regulatory oversight. As designers in particular, we must take responsibility to imagine and invite public scrutiny and policy constraints as part of respectfully co-constructing space. designating low-speed pathways as a form of policy geofencing may help preserve safe pedestrian movement. However, as with pedestrian classification widening to PDDs, geofencing comes with its own risks of segregating people and transportation options, which may easily perpetuate racist redlining practices [30]. Along with ongoing community input, policy to geofence at the level of pathways rather than neighborhoods may serve to liberate rather than foreclose pedestrian access. In summary, the ability for micromobility to continue to exist on our sidewalks and streets depends on robust policy provisions anticipating and dictating the downstream effects and likely consequences of these devices roving pedestrian pathways-as testing ground some are essential commute for others.

\subsection{Reincarnations of Inaccessible Infrastructure}

Operators and government workers alike spoke of difficulties communicating with companies about mis-parked and broken vehicles, 
culminating in a variety of responses. Some government programs intervened to monitor or allow easier reporting to those already familiar with government communication channels. However, operators described being disincentivized from reporting bikes unfit for riders to the point that designating vehicles as broken could result in lost wages. With per-vehicle charging rates changing depending on demand and company policy, operators described choosing to refresh supply with broken vehicles rather than report them for repair.

Beyond their rideability, micromobility vehicles' presence in public space impacted disabled people not intent on using them. They created disruptions and blocked paths, reincarnating long-fought battles by disabled people to occupy public space [25, 89]. Though advertised as new and innovative, in this way, micromobility was served as a haunting rebirth of inaccessible infrastructure. The inaccessibility of vehicles themselves and their occupation of accessible space drew out the assumptions of micromobility program planners about the value of space and what might constitute the right means to improve it. While planners and micromobility managers agreed that public space was over-allocated to automobiles, they created new tension by taking vehicles onto the curb. Such conflicts should not only drive conversation, but also investments into the infrastructure necessary to sustain alternative transportation options.

Micromobility's power to keep wheelchair users from ascending curb cuts represents a particularly egregious and ironic perspective on potential impacts of accessible design. The curb cut has particular significance in disability history. Specifically, they have come to symbolize the disability rights movement as their construction became an iconic symbol of disabled people's fervor. Images of disabled people and allies hammering concrete until it gave way to streets crossable by wheelchairs combined with other organized physical resistances startled viewers [89]. Such force defied disabled bodies' presumed passivity, and these efforts, according to many proponents of universal design, have paid off. Now, the orderly installation of curb cuts is instantiated in law and are propagated as a benefit to everyone. Thanks to curb cuts, disabled people's resistance and ingenuity is now enjoyed by people wheeling strollers and suitcases, for example [49, 72].

However, wheelchair ramps as bike parking and robot rests point to concerning futures for the very spaces disabled people have fought so hard to gain. Curb cuts and other accessible infrastructure remain scant. Indeed, data collections of sidewalk conditions contribute to efforts to raise awareness on the inaccessible contemporary cities and are seen as integral to identifying areas of improvement $[73,80]$. Such projects are taken up as open citizen science initiatives, inviting collective participation toward more accessible cities. But micromobility deployments, according to our interviews and archival traces, demonstrate that such open datafication may underpin the development of yet more inaccessible infrastructure. Indeed, autonomous robots would not maneuver streets if not for curb cuts and importantly, if not for data about their locale. The maintenance of accessible public space in this case involves not only the physical materials of curb cuts but the reason for their shape and the implications of their open datafication. We challenge the presumed universal good of openness. Appropriating disabled spaces to enable access barriers-in-motion dishonors the history and activism required to create such spaces. Fast launches of e-scooters and PDDs lead to questions of how HCI may carefully reimagine public space as to expand access while equitably preserving existing pathways upon which disabled people already rely. HCI researchers involved in the creation and dissemination of data sets may first ask, "who needs to know?" What coalitions may be forged with communities that will benefit from knowing which spaces are currently accessible and which partners are committed to remediating inaccessible pathways? These proposals are not to reduce transparency or withhold access to data from those who need it, but to recognize and respond to the uneven power different stakeholders have to act on information. With such data, disabled citizens may individually route plan while research groups and resourced companies may speedily map pilot areas for vehicles that have yet been informed by disabled people. Attending to these power differentials may involve collaboratively developing and enforcing standards-of-use to promote data stewardship that is in service of those who are at most risk if the information is repurposed without their input.

\subsection{Refusal as Design Response}

Our disabled interlocutors readily critiqued micromobility as a materialized form of neoliberal disinvestment - a move away from publicly managed services to privatized offerings. Company-city consortia and media-heavy kick-off events depicted a culmination of design and development targeted at meeting the demands of growing cities with the speed and operations capacity of a profitmaking venture. But these outlets often neglect the voices of those who did not find intrinsic value in such launches. It's quickly clear from reviewing the stakeholder list of the Pittsburgh Mobility Collective, for example, that the group falls short of equitable representation (many of its members are simply company representatives). Scholars of participatory and sustainable design contend that ongoing community participation may harmonize transfers from labs to public life [5], yet the uneven character of deployments already underway begs further interrogation - as do the consequences of arbitrating community participation.

If covered by news media, the announcement of micromobility in local press often took on a celebratory tone, while positioning its introduction as a foregone conclusion. There was little room to express concern, push back, or debate the merits of these devices through official channels. Instead, residents' opposition took other forms such as Twitter threads or "vandalism". However, the boosterism around early media reporting reappeared in the promicromobility responses, as was the case with Emily, where residents serve to reinforce the corporations' party lines. The power of micromobility programs is in reshaping not only the city streets, but also public discourse. As a consequence of social media backlash, Emily felt unsafe and disabled interlocutors in Seattle became responsible to assert, again, their right to move through public space unencumbered.

Thinking with these tensions on how technology is transferred and how opposition can manifest, we see an opportunity to reflect on the need for designers and developers to recognize responses like these as generative forms of communication about product 
and deployment processes. As others have contended, reading resistance as part of design is preliminary to widening the scope through which we learn and intervene [50]. Yet, re-characterizing forms of participation as legitimate is itself another exertion of designer power to categorize and decide what is taken seriously. Inviting participation may itself become a form of exploitative signaling inclusive intent without meaningful outcomes $[4,64]$. We complement recognition of activism as design communication to call for a care to be taken in crafting not only policy and messaging, but also interventions in the first place. Promotions that characterize products in universal positive terms demote resistance. As we learned, the downstream impact may at best eradicate opportunities to learn and at worst could become dangerous. Instead, messaging may anticipate and even invite resistances as forms of communication and redesign.

Our insights contribute to understanding the specific moments during partnerships when power and products transition and close off. Left open, careful processes could instead be interspersed with opportunities for those beyond the internal team to meaningfully engage in design decision-making, including when that might mean resisting or abandoning the technology. Recent feminist design scholarship emphasizes the role of refusal as a contribution [34, 50]. Taking on this perspective in a development process would mean attending to the concerns raised by Emily and our other disabled interlocutors as design labor. In a related example of halting tech hype and expansion, community residents, labor union organizers, and local politicians in Queens joined together to push back against plans for Amazon to build a new headquarters in a neighborhood of the borough [37]. Here, access to public venues like city council meetings allowed for residents to decry a move they felt was happening behind their backs. Ultimately, despite expansive resources, the company pulled out due to continued pressure and resistance.

In this paper, we re-characterized planning for deployments as opportunities to anticipate and prevent negative impacts, rather than treating rollouts as experimental games of 'wait and see.' In line with feminist and justice-oriented HCI, we call on the DIS community to widen the forms of civic engagement we consider such that our contributions extend to debates on tech governance and the protection of increasingly rare accessible space. As long as systemic barriers continue to limit disabled involvement in design and the vision of users reflects development teams, the relationship between disability and design will remain contentious. Alongside tactics of refusal, the integration of disabled voices at all levels of the process is necessary to developing accessible designs that minimize harmful, downstream impacts. Such shifts in design priorities demand paying respects to disability history, setting standards-ofuse for the tools we release to raise awareness about (in)accessible space such that they aren't misappropriated to fast track novel access barriers and to read resistant and avoidant use as forms of design communication of community needs.

\section{CONCLUSION}

In this paper, we have situated access to public space as the basis to examine micromobility's evolution with focus on two municipalities, Pittsburgh, PA and Seattle, WA. Through 24 interviews with public space activists, disabled people, government workers, commercial employees, and operators of micromobility vehicles, we have animated associated media accounts and activism with very personal and consequential impact contemporary forms of corporatized micromobility. Micromobility has promise to enhance transportation options, support municipal goals toward ecofriendly landscapes, and offer flexibility by relieving burdens of vehicle ownership on citizens. Personal delivery devices allow goods to weave more seamlessly through busy streets and sidewalks and offer contactless mediums for delivery, which has gained importance during a global pandemic of a contagious virus. However, disabled people we spoke with are often unable to ride micromobility and are further blocked by vehicles and personal delivery devices in their pathways. Sometimes, these obstacles became safety hazards. But as disabled people organized attendant activism to raise awareness of and demand relief of these new access barriers, the hoopla with which micromobility hit the streets as convenient and innovative curtailed resistance. These disabled interlocutors are retreading a long activist road to reclaim their right to participate in public. Reading these recent developments to public spaces through disability history, we call on HCI researchers to be accountable to the people impacted by our interventions, even when they are non- or resistant users.

\section{ACKNOWLEDGMENTS}

We thank our interviewees for providing us insight on micromobility's growth from so many-disability, activist, government, commercial-perspectives. This work was made possible in part by the support of NSF grant \# 2037348.

\section{REFERENCES}

[1] Emily Ackerman. 2019. Twitter Post. @emilyeackerman. Retrieved April 26, 2021 from https://twitter.com/emilyeackerman/status/1186363305851576321

[2] Emily Ackerman. 2019. Lessons From My Standoff With an Autonomous Sidewalk Robot. Bloomberg.com. Retrieved January 21, 2021 from https://www.bloomberg.com/news/articles/2019-11-19/why-tech-needsmore-designers-with-disabilities

[3] Adaptive Biketown. How Adaptive Biketown's Bicycle Program Works. Adaptive Biketown. Retrieved April 26, 2021 from https://adaptivebiketown.com/howit-works

[4] Alex Ahmed. 2020. We Will Not Be Pacified Through Participation. Tech Otherwise. https://doi.org/10.21428/93b2c832.e4aa9a47

[5] Hamed S. Alavi, Denis Lalanne, and Yvonne Rogers. 2020. The Five Strands of Living Lab: A Literature Study of the Evolution of Living Lab Concepts in HCI. ACM Transactions on Computer-Human Interaction 27, 2: 10:1-10:26. https://doi.org/10.1145/3380958

[6] Ryan P. Aument. 2020. Pennsylvania Senate Bill 1199. Retrieved February 21, 2021 from https://www.legis.state.pa.us/cfdocs/billinfo/billInfo.cfm?syear= $2019 \&$ sind $=0 \&$ body $=$ S\&type $=\mathrm{B} \& \mathrm{bn}=1199$

[7] Shiri Azenkot, Richard E. Ladner, and Jacob O. Wobbrock. 2011. Smartphone haptic feedback for nonvisual wayfinding. In The proceedings of the 13th international ACM SIGACCESS conference on Computers and accessibility (ASSETS '11), 281-282. https://doi.org/10.1145/2049536.2049607

[8] Giulia Barbareschi, Sibylle Daymond, Jake Honeywill, Aneesha Singh, Dominic Noble, Nancy N. Mbugua, Ian Harris, Victoria Austin, and Catherine Holloway. 2020. Value beyond function: analyzing the perception of wheelchair innovations in Kenya. In The 22nd International ACM SIGACCESS Conference on Computers and Accessibility (ASSETS '20), 1-14. https://doi.org/10.1145/3373625. 3417017

[9] Giulia Barbareschi, Ben Oldfrey, Long Xin, Grace Nyachomba Magomere, Wycliffe Ambeyi Wetende, Carol Wanjira, Joyce Olenja, Victoria Austin, and Catherine Holloway. 2020. Bridging the Divide: Exploring the use of digital and physical technology to aid mobility impaired people living in an informal settlement. In The 22nd International ACM SIGACCESS Conference on Computers and Accessibility (ASSETS '20), 1-13. https://doi.org/10.1145/3373625.3417021

[10] Beau Berman. 2018. "Scoobi" on-demand electric scooter rentals arrive in Pittsburgh. WTAE. Retrieved February 11, 2021 from 
https://www.wtae.com/article/scoobi-on-demand-electric-scooter-rentalsarrive-in-pittsburgh/22555123

[11] Megan Campbell, Cynthia Bennett, Caitlin Bonnar, and Alan Borning. 2014. Where's my bus stop? supporting independence of blind transit riders with StopInfo. In Proceedings of the 16th international ACM SIGACCESS conference on Computers \& accessibility (ASSETS '14), 11-18. https://doi.org/10.1145/2661334. 2661378

[12] Daniel Castro. 2019. E-Scooter Bans Show Cities Are Hesitant to Embrace Innovation. GovTech. Retrieved April 26, 2021 from https://www.govtech.com/opinion/E-Scooter-Bans-Show-Cities-AreHesitant-to-Embrace-Innovation.html

[13] Annie Chang, Luis Miranda-Moreno, Lijun Sun, and Regina Clewlow. 2019. Trend or Fad? Deciphering the Enablers of Micromobility in the U.S. SAE International.

[14] Wen-Wei Chang, Elisa Giaccardi, Lin-Lin Chen, and Rung-Huei Liang. 2017. "Interview with Things": A First-thing Perspective to Understand the Scooter's Everyday Socio-material Network in Taiwan. In Proceedings of the 2017 Conference on Designing Interactive Systems (DIS '17), 1001-1012. https: //doi.org/10.1145/3064663.3064717

[15] Kathy Charmaz and Richard G. Mitchell. 2001. Grounded Theory in Ethnography. In Handbook of Ethnography, Paul Atkinson, Amanda Coffey, Sara Delamont, Lyn Lofland, John Lofland and Professor Lyn H. Lofland (eds.). SAGE.

[16] Simone Chess, Alison Kafer, Jessie Quizar, and Mattie Richardson. 2010. Calling all restroom revolutionaries. In That's Revolting!: Queer Strategies for Resisting Assimilation, Pasha Malla (ed.). ReadHowYouWant.com.

[17] City of Pittsburgh. 2019. Pittsburgh Announces New Mobility Demonstration to Expand Sustainable Transportation Options in City Neighborhoods. City of Pittsburgh. Retrieved February 11, 2021 from http://pittsburghpa.gov/pressreleases/press-releases.html?id=3152

[18] CMU Human-Computer Interaction Institute. 2020. The Accessibility Gap for Tech Users and Developers. Retrieved April 26, 2021 from https://www.youtube. $\mathrm{com} /$ watch?v=MZtYriuua3U

[19] Gabe Cohen. 2019. Blocked by bikes: People with disabilities frustrated by bike share hazards. KOMO News. Retrieved April 26, 2021 from https://komonews.com/news/local/blocked-by-bikes-people-withdisabilities-frustrated-by-bike-share-hazards

[20] David Conti. 2013. Pittsburgh Bike Share Partnership awaits corporate sponsor | TribLIVE.com. TribLive. Retrieved February 11, 2021 from https://archive.triblive.com/local/pittsburgh-allegheny/pittsburgh-bikeshare-partnership-awaits-corporate-sponsor/\#axzz2eOuKVQoZ

[21] Critical Design Lab. Radical Standards. Critical Design Lab. Retrieved Febru-ary 11, 2021 from https://www.mapping-access.com/radical-standards

[22] Nik DeCosta-Klipa. 2018. What happens if you ride one of those Bird scooters into Boston? Boston.com. Retrieved from https://www.boston.com/news/localnews/2018/07/23/bird-scooters-boston

[23] Nicole DuPuis, Jason Griess, and Connor Klein. 2019. Micromobility in Cities: A History and Policy Overview. National League of Cities. Retrieved February 11, 2021 from https://trid.trb.org/view/1603755

[24] Editorial Staff of BBC News. 2021. Visually-impaired woman "frightened" by e-scooters. BBC News. Retrieved April 26, 2021 from https://www.bbc.com/ news/uk-england-nottinghamshire-56684033

[25] Editorial Staff of CBS SF. 2014. BART Gives Public A Look At "Fleet Of The Future" For 1st Time. CBS SF Bay Area. Retrieved February 11, 2021 from https://sanfrancisco.cbslocal.com/2014/04/16/bart-gives-public-a-look-at-fleetof-the-future-for-1st-time/

[26] Editorial staff of myBurgh. 2019. Where can a Scoobi be parked? - City of Pittsburgh, PA. myBurgh. Retrieved February 11, 2021 from https://pittsburghpa qscend.com $/ 311 /$ knowledgebase/article $/ 343079$

[27] Alexander Fiannaca, Ilias Apostolopoulous, and Eelke Folmer. 2014. Headlock: a wearable navigation aid that helps blind cane users traverse large open spaces. In Proceedings of the 16th international ACM SIGACCESS conference on Computer \& accessibility (ASSETS '14), 19-26. https://doi.org/10.1145/2661334.2661453

[28] German Flores and Roberto Manduchi. 2018. A Public Transit Assistant for Blind Passengers: Development and Experiments. Retrieved February 11, 2021 from https://escholarship.org/uc/item/0x5980c8

[29] Richard Florida. 2018. Pittsburgh's Bill Peduto: "There's No Easy Fix" for Inequality. Bloomberg.com. Retrieved February 11, 2021 from https://www.bloomberg.com/news/articles/2018-02-08/pittsburgh-s-billpeduto-on-avs-and-an-economy-for-all

[30] Sarah E. Fox, Meredith Lampe, and Daniela K. Rosner. 2018. Parody in Place: Exposing Socio-spatial Exclusions in Data-Driven Maps with Design Parody. In Proceedings of the 2018 CHI Conference on Human Factors in Computing Systems (CHI '18), 1-13. https://doi.org/10.1145/3173574.3173896

[31] Sarah E. Fox, Kiley Sobel, and Daniela K. Rosner. 2019. Managerial Visions: Stories of Upgrading and Maintaining the Public Restroom with IoT. In Proceedings of the 2019 CHI Conference on Human Factors in Computing Systems (CHI '19), 1-15. https://doi.org/10.1145/3290605.3300723
[32] Guo Freeman, Jeffrey Bardzell, Shaowen Bardzell, Szu-Yu (Cyn) Liu, Xi Lu, and Diandian Cao. 2019. Smart and Fermented Cities: An Approach to Placemaking in Urban Informatics. In Proceedings of the 2019 CHI Conference on Human Factors in Computing Systems (CHI '19), 1-13. https://doi.org/10.1145/ 3290605.3300274

[33] Tom Fucoloro. 2017. Mayor Murray cancels bike share expansion, will shut down Pronto March 31. Seattle Bike Blog. Retrieved February 11, 2021 from https://www.seattlebikeblog.com/2017/01/13/mayor-murray-cancelsbike-share-expansion-will-shut-down-pronto-march-31/

[34] Patricia Garcia, Tonia Sutherland, Marika Cifor, Anita Say Chan, Lauren Klein, Catherine D'Ignazio, and Niloufar Salehi. 2020. No: Critical Refusal as Feminist Data Practice. In Conference Companion Publication of the 2020 on Computer Supported Cooperative Work and Social Computing. Association for Computing Machinery, New York, NY, USA, 199-202. Retrieved February 11, 2021 from https://doi.org/10.1145/3406865.3419014

[35] Christopher Gavin. 2019. Boston City Council approves electric scooter, micro-mobility ordinance. Boston.com. Retrieved April 26, 2021 from https://www.boston.com/news/local-news/2019/03/27/boston-city-councilgreen-light-electric-scooter-micro-mobility-ordinance

[36] Haben Girma. 2020. The robots occupying our sidewalks. TechCrunch. Retrieved April 26, 2021 from https://social.techcrunch.com/2020/08/11/the-robotsoccupying-our-sidewalks/

[37] J. David Goodman. 2019. Amazon Pulls Out of Planned New York City Headquarters. The New York Times. Retrieved April 26, 2021 from https://www. nytimes.com/2019/02/14/nyregion/amazon-hq2-queens.html

[38] Ben Green. 2019. The Smart Enough City: Putting Technology in Its Place to Reclaim Our Urban Future. MIT Press.

[39] Heidi Groover. 2019. Frustrated by all those bikes in the middle of Seat-tle sidewalks? You're not alone. The Seattle Times. Retrieved April 26, 2021 from https://www.seattletimes.com/seattle-news/transportation/frustrated-byall-those-bikes-in-the-middle-of-seattle-sidewalks-youre-not-alone/

[40] João Guerreiro, Dragan Ahmetovic, Kris M. Kitani, and Chieko Asakawa. 2017. Virtual Navigation for Blind People: Building Sequential Representations of the Real-World. In Proceedings of the 19th International ACM SIGACCESS Conference on Computers and Accessibility (ASSETS '17), 280-289. https://doi. org $/ 10.1145 / 3132525.3132545$

[41] Richard Guy and Khai Truong. 2012. CrossingGuard: exploring information content in navigation aids for visually impaired pedestrians. In Proceedings of the SIGCHI Conference on Human Factors in Computing Systems (CHI '12), 405-414. https://doi.org/10.1145/2207676.2207733

[42] Aimi Hamraie. 2017. Building Access: Universal Design and the Politics of Disability. Univ Of Minnesota Press, Minneapolis.

[43] Aimi Hamraie. 2018. Mapping Access: Digital Humanities, Disability Justice, and Sociospatial Practice. American Quarterly 70, 3: 455-482. https://doi.org/10. 1353/aq.2018.0031

[44] Aimi Hamraie and Kelly Fritsch. 2019. Crip Technoscience Manifesto. Catalyst: Feminism, Theory, Technoscience 5, 1: 1-33. https://doi.org/10.28968/cftt. v5i1.29607

[45] Naomi Harrington, Laura Antuña, and Y. Coady. 2012. ABLE Transit: A Mobile Application for Visually Impaired Users to Navigate Public Transit. 2012 Seventh International Conference on Broadband, Wireless Computing, Communication and Applications. https://doi.org/10.1109/BWCCA.2012.72

[46] Mark Harris. 2018. The Bike Share War Is Shaking Up Seattle Like Nowhere Else. Wired. Retrieved February 11, 2021 from https://www.wired.com/story/thebike-share-war-is-shaking-up-seattle-like-nowhere-else/

[47] Megan Harris. 2015. "Healthy" Beginning For Long-Awaited Pittsburgh Bike Share | 90.5 WESA. 90.5 WESA. Retrieved February 11, 2021 from https://www.wesa.fm/post/healthy-beginning-long-awaited-pittsburghbike-share\#stream $/ 0$

[48] Sara Heitlinger, Nick Bryan-Kinns, and Rob Comber. 2018. Connected seeds and sensors: co-designing internet of things for sustainable smart cities with urban food-growing communities. In Proceedings of the 15th Participatory Design Conference: Short Papers, Situated Actions, Workshops and Tutorial - Volume 2 (PDC '18), 1-5. https://doi.org/10.1145/3210604.3210620

[49] Sara Hendren. 2020. What Can a Body Do?: How We Meet the Built World. Riverhead Books, New York.

[50] Sarah Homewood. 2018. Designing for the Changing Body: A Feminist Exploration of Self-Tracking Technologies. In Extended Abstracts of the 2018 CHI Conference on Human Factors in Computing Systems (CHI EA '18), 1-4. https://doi.org/10.1145/3170427.3173031

[51] Representative Sara Innamorato. 2020. Presenation on PA Senate Bill 1199 and House Bill 2699 Personal Delivery Drones.

[52] Sheila Jasanoff. 2016. The Ethics of Invention: Technology and the Human Future. W. W. Norton \& Company.

[53] Cecilia Kang. 2016. No Driver? Bring It On. How Pittsburgh Became Uber's Testing Ground. The New York Times. Retrieved February 11, 2021 from https://www.nytimes.com/2016/09/11/technology/no-driver-bring-it-onhow-pittsburgh-became-ubers-testing-ground.html 
[54] Richard Kempton. 2007. Provo: Amsterdam's Anarchist Revolt. Autonomedia, Brooklyn, NY

[55] Lynn Kirabo, Elizabeth J. Carter, and Aaron Steinfeld. 2020. "You are asking me to pay for my legs": Exploring the Experiences, Perceptions, and Aspirations of Informal Public Transportation Users in Kampala and Kigali. In Proceedings of the 3rd ACM SIGCAS Conference on Computing and Sustainable Societies (COMPASS '20), 136-147. https://doi.org/10.1145/3378393.3402269

[56] Julius Kizzee. 2019. 'A fantastic addition': Bolt Scooters launched in Richmond. 8News. Retrieved February 11, 2021 from https://www.wric.com/news/ local-news/a-fantastic-addition-bolt-scooters-launched-in-richmond/

[57] Ava KofmanAva Kofman. 2018. Are New York's Free LinkNYC Internet Kiosks Tracking Your Movements? The Intercept. Retrieved February 11, 2021 from https://theintercept.com/2018/09/08/linknyc-free-wifi-kiosks/

[58] Sandjar Kozubaev, Fernando Rochaix, Carl DiSalvo, and Christopher A. Le Dantec. 2019. Spaces and Traces: Implications of Smart Technology in Public Housing. In Proceedings of the 2019 CHI Conference on Human Factors in Computing Systems (CHI '19), 1-13. https://doi.org/10.1145/3290605.3300669

[59] Claire Lampen. 2019. Yes, LinkNYC Kiosks Are Giant Data-Harvesting Surveillance Cameras, Obviously. Gothamist. Retrieved February 11, 2021 from https:/gothamist.com/news/yes-linknyc-kiosks-are-giant-data-harvestingsurveillance-cameras-obviously

[60] Nicole Lawton. 2019. Blind and visually impaired people want escooters off the footpath for good. Stuff. Retrieved April 26, 2021 from https://www.stuff.co.nz/national/111820308/blind-and-visually-impairedpeople-want-escooters-off-the-footpath-for-good

[61] Can Liu, Mara Balestrini, and Giovanna Nunes Vilaza. 2019. From Social to Civic: Public Engagement with IoT in Places and Communities. In Social Internet of Things, Alessandro Soro, Margot Brereton and Paul Roe (eds.). Springer International Publishing, Cham, 185-210. https:// doi.org/10.1007/978-3-319-94659-7 10

[62] Andreas Löcken, Pascal Brunner, and Ronald Kates. 2020. Impact of Hand Signals on Safety: Two Controlled Studies With Novice E-Scooter Riders. In 12th International Conference on Automotive User Interfaces and Interactive Vehicular Applications, 132-140. Retrieved February 11, 2021 from https://doi.org/10.1145/ 3409120.3410641

[63] Aarian Marshall. 2020. Amazon and FedEx Push to Put Delivery Robots on Your Sidewalk. Wired. Retrieved February 11, 2021 from https://www.wired. com/story/amazon-fedex-delivery-robots-your-sidewalk/

[64] Shannon Mattern. 2020. Post-It Note City. Places fournal. https://doi.org/10. $22269 / 200211$

[65] Amy Moreno. 2018. Seattle bikeshare expansion raises concerns about blocking mobility. King5 News. Retrieved April 26, 2021 from https://www.king5.com/article/news/local/seattle-bikeshare-expansionraises-concerns-about-blocking-mobility/281-575362921

[66] National Association of City Transportation Officials. 2018. Shared Micromobility in the U.S.: 2018. National Association of City Transportation Officials. Retrieved February 11, 2021 from https://nacto.org/shared-micromobility-2018

[67] Stephen Nessen. 2021. City Launches First E-Scooter Share Pilot This Summer In The Bronx. Gothamist. Retrieved April 26, 2021 from https://gothamist.com/ news/city-launches-first-e-scooter-share-pilot-bronx-summer

[68] Kalyn Norwood. 2019. Blind and visually impaired ask Austin scooter users to be more careful. KVUE. Retrieved April 26, 2021 from https://www.kvue.com/article/news/blind-and-visually-impaired-ask-austin scooter-users-to-be-more-careful/269-3dd45d86-12ae-4420-bb38-71498cbf4ee9

[69] Mike O'Brien. 2019. A Resolution requesting that the Seattle Department of Transportation develop a budget proposal for creating on-street bike and e-scooter parking. Retrieved April 26, 2021 from http://seattle.legistar.com/View ashx?M=F\&ID=7731705\&GUID=7955818C-F326-4A45-9AE0-73B077ABE987

[70] Author: Outdoors for All Foundation. 2020. Adaptive Cycling Center's Record-Breaking Summer! Outdoors for All Foundation. Retrieved April 26 2021 from https://outdoorsforall.org/2020/04/adaptive-cycling-centers-recordbreaking-summer/

[71] Gloria Pazmino. 2019. LinkNYC Kiosks are Losing Money - and There are Surveillance Fears. Retrieved February 11, 2021 from https://www.ny1.com/nyc/all-boroughs/politics/2019/05/09/linknyc-kioskssurveillance-questions-about-cameras-recording-kiosks-also-losing-money

[72] Graham Pullin. 2011. Design Meets Disability. The MIT Press, Cambridge, Mass.

[73] Radical Access Mapping Project. 2015. About RAMP. radical access mapping project. Retrieved February 11, 2021 from https://radicalaccessiblecommunities. wordpress.com/about-ramp/

[74] Christian August Reksten-Monsen and Jun Han. 2019. Towards Precise Localization of E-Scooters Using Sidewalk Ramps (poster). In Proceedings of the 17th Annual International Conference on Mobile Systems, Applications, and Services (MobiSys '19), 628-629. https://doi.org/10.1145/3307334.3328660

[75] Sunil Rodger, Dan Jackson, John Vines, Janice McLaughlin, and Peter Wright. 2019. JourneyCam: Exploring Experiences of Accessibility and Mobility among
Powered Wheelchair Users through Video and Data. In Proceedings of the 2019 CHI Conference on Human Factors in Computing Systems (CHI '19), 1-15. https: //doi.org/10.1145/3290605.3300860

[76] Oscar J. Romero, Alexander Haig, Lynn Kirabo, Qian Yang, John Zimmerman, Anthony Tomasic, and Aaron Steinfeld. 2020. A Long-Term Evaluation of Adaptive Interface Design for Mobile Transit Information. In 22nd International Conference on Human-Computer Interaction with Mobile Devices and Services (MobileHCI '20), 1-11. https://doi.org/10.1145/3379503.3403536

[77] Rooted In Rights. 2019. Bike Share Parking: Do the Right Thing! Rooted in Rights. Retrieved April 26, 2021 from https://rootedinrights.org/video/bikeshare-parking-do-the-right-thing/

[78] Simon Saddier, Zachary Patterson, Alex Johnson, and Natalie Wiseman. 2017. Fickle or Flexible?: Assessing Paratransit Reliability with Smartphones in Accra Ghana. Transportation Research Record 2650, 1: 9-17. https://doi.org/10.3141/ 2650-02

[79] Manaswi Saha, Devanshi Chauhan, Siddhant Patil, Rachel Kangas, Jeffrey Heer, and Jon E. Froehlich. 2021. Urban Accessibility as a Socio-Political Problem: A Multi-Stakeholder Analysis. Proceedings of the ACM on Human-Computer Interaction 4, CSCW3: 209:1-209:26. https://doi.org/10.1145/3432908

[80] Manaswi Saha, Michael Saugstad, Hanuma Teja Maddali, Aileen Zeng, Ryan Holland, Steven Bower, Aditya Dash, Sage Chen, Anthony Li, Kotaro Hara, and Jon Froehlich. 2019. Project Sidewalk: A Web-based Crowdsourcing Tool for Collecting Sidewalk Accessibility Data At Scale. In Proceedings of the 2019 CHI Conference on Human Factors in Computing Systems (CHI '19), 1-14. https: //doi.org/10.1145/3290605.3300292

[81] Hiroki Sato, Young ah Seong, Ryosuke Yamamura, Hiromasa Hayashi, Katsuhiro Hata, Hisato Ogata, Ryuma Niiyama, and Yoshihiro Kawahara. 2020. Soft yet Strong Inflatable Structures for a Foldable and Portable Mobility. In Extended Abstracts of the 2020 CHI Conference on Human Factors in Computing Systems (CHI EA '20), 1-4. https://doi.org/10.1145/3334480.3383147

[82] Herrie Schalekamp. 2017. Lessons from building paratransit operators' capac-ity to be partners in Cape Town's public transport reform process. Transportation Research Part A: Policy and Practice 104: 58-66. https://doi.org/10.1016/j.tra.2017. 08.002

[83] Susan M. Schweik. 2010. The Ugly Laws: Disability in Public. New York University Press, New York; Chesham.

[84] Seattle Department of Transportaiton. 2019. 2019 Quarter 2 Bike Share Summary Report. City of Seattle. Retrieved from https:// www.seattle.gov/Documents/Departments/SDOT/BikeProgram/2019Q2_ BikeShare_Summary_Report.pdf

[85] Seattle Department of Transportaiton. 2019. 2019 Quarter 3 Bike Share Summary Report. City of Seattle. Retrieved from https:// www.seattle.gov/Documents/Departments/SDOT/BikeProgram/2019Q3 BikeShare_Summary_Report.pdf

[86] Seattle Department of Transportaiton. 2019. 2019 Quarter 1 Bike Share Summary Report. City of Seattle. Retrieved from https:// www.seattle.gov/Documents/Departments/SDOT/BikeProgram/2019Q1_ BikeShare_Summary_Report.pdf

[87] Seattle Department of Transportation. Bike Share - Transportation | seattle.gov. Seattle.gov. Retrieved February 11, 2021 from https://www.seattle.gov/ transportation/projects-and-programs/programs/bike-program/bike-share

[88] Seattle Department of Transportation. Scooter Share - Transporta-tion | seattle.gov. Seattle.gov. Retrieved February 11, 2021 from https:// www.seattle.gov/transportation/projects-and-programs/programs/newmobility-program/scooter-share

[89] Joseph P. Shapiro. 1994. No Pity: People With Disabilities Forging a New Civil Rights Movement. Times Books.

[90] Andrew Small. 2016. Why Portland, of All Places, Came Late to Bike-Share. Bloomberg.com. Retrieved April 26, 2021 from https:// www.bloomberg.com/news/articles/2016-07-27/why-portland-waited-solong-to-launch-its-new-bike-share-system-biketown

[91] Alex S. Taylor, Siân Lindley, Tim Regan, David Sweeney, Vasillis Vlachokyriakos, Lillie Grainger, and Jessica Lingel. 2015. Data-in-Place: Thinking through the Relations Between Data and Community. In Proceedings of the 33rd Annual ACM Conference on Human Factors in Computing Systems. Association for Computing Machinery, New York, NY, USA, 2863-2872. Retrieved February 11, 2021 from https://doi.org/10.1145/2702123.2702558

[92] Nick Taylor, Justin Marshall, Alicia Blum-Ross, John Mills, Jon Rogers, Paul Egglestone, David M. Frohlich, Peter Wright, and Patrick Olivier. 2012. Viewpoint: empowering communities with situated voting devices. In Proceedings of the SIGCHI Conference on Human Factors in Computing Systems (CHI '12), 1361-1370. https://doi.org/10.1145/2207676.2208594

[93] Hung-Yu Tseng, Rong-Hao Liang, Liwei Chan, and Bing-Yu Chen. 2015 LEaD: Utilizing Light Movement as Peripheral Visual Guidance for Scooter Navigation. In Proceedings of the 17th International Conference on HumanComputer Interaction with Mobile Devices and Services (MobileHCI '15), 323-326. https://doi.org/10.1145/2785830.2785831 
[94] Sylvaine Tuncer and Barry Brown. 2020. E-scooters on the Ground: Lessons for Redesigning Urban Micro-Mobility. In Proceedings of the 2020 CHI Conference on Human Factors in Computing Systems (CHI '20), 1-14. https://doi.org/10.1145/ 3313831.3376499

[95] United States Department of Justice Civil Rights Division. 2011. Public Accommodations and Commercial Facilities (Title III). Information and Technical Assistance on the Americans with Disabilities Act. Retrieved February 11, 2021 from https://www.ada.gov/ada_title_III.htm

[96] US Deparment of Transportation. 2016. Smart City Challenge: Lessons for Building Cities of the Future / US Department of Transportation. Retrieved February 11, 2021 from https://www.transportation.gov/policy-initiatives/smartcity/ smart-city-challenge-lessons-building-cities-future

[97] Vasilis Vlachokyriakos, Rob Comber, Karim Ladha, Nick Taylor, Paul Dunphy, Patrick McCorry, and Patrick Olivier. 2014. PosterVote: expanding the action repertoire for local political activism. In Proceedings of the 2014 conference on Designing interactive systems (DIS '14), 795-804. https://doi.org/10.1145/2598510. 2598523

[98] Jillian Weise. 2018. Common Cyborg. Granta. Retrieved February 11, 2021 from https://granta.com/common-cyborg/

[99] Eric Westervelt. 2019. Ride-Hailing Revolution Leaves Some People With Disabilities Behind. NPR.org. Retrieved February 11, 2021 from https://www.npr.org/2019/08/21/753034337/ride-hailing-revolution-leavessome-people-with-disabilities-behind

[100] Cedric Deslandes Whitney, Teresa Naval, Elizabeth Quepons, Simrandeep Singh, Steven R. Rick, and Lilly Irani. 2021. HCI Tactics for Politics from Below: Meeting the Challenges of Smart Cities. In Proceedings of the SIGCHI Conference on Human Factors in Computing Systems. Retrieved February 11, 2021 from https://escholarship.org/uc/item/83r8r0j0
[101] Bess Williamson. 2019. Accessible America: A History of Disability and Design. NYU Press, New York.

[102] Molly Wright. 2019. FREE adaptive cycle rentals through a new partnership with Outdoors for All. Seattle Department of Transportation Blog. Retrieved April 26, 2021 from https://sdotblog.seattle.gov/2019/05/07/expanded-bikeaccess-for-all-free-adaptive-cycle-rentals-through-a-new-partnership-withoutdoors-for-all/

[103] Rayoung Yang, Sangmi Park, Sonali R. Mishra, Zhenan Hong, Clint New-som, Hyeon Joo, Erik Hofer, and Mark W. Newman. 2011. Supporting spatial awareness and independent wayfinding for pedestrians with visual impairments. In The proceedings of the 13th international ACM SIGACCESS conference on Computers and accessibility (ASSETS '11), 27-34. https://doi.org/10.1145/2049536. 2049544

[104] Meg Young, Michael Katell, and P. M. Krafft. 2019. Municipal surveillance regulation and algorithmic accountability. Big Data \& Society 6, 2: 2053951719868492. https://doi.org/10.1177/2053951719868492

[105] Meg Young, Luke Rodriguez, Emily Keller, Feiyang Sun, Boyang Sa, Jan Whittington, and Bill Howe. 2019. Beyond Open vs. Closed: Balancing Individual Privacy and Public Accountability in Data Sharing. In Proceedings of the Conference on Fairness, Accountability, and Transparency (FAT* '19), 191-200. https://doi.org/10.1145/3287560.3287577

[106] Anna Zivarts. 2019. Open Letter to Seattle Mayor Durkan on Scooter Share. Rooted in Rights. Retrieved April 26, 2021 from https://rootedinrights.org/ scooters/

[107] Sarah F. Rose. 2017. No Right to Be Idle: The Invention of Disability, 1840s-1930s. University of North Carolina Press, Chapel Hill.

[108] Accessible Manhattan. Gale Brewer. Retrieved February 11, 2021 from https:/www.manhattanbp.nyc.gov/accessible-manhattan/ 